\title{
Metáforas acuáticas en la escritura de Paul Nizan
}

\author{
Figuerola Cabrol, M. Carme
}

Universitat de Lleida, cfiguerola@filcef.udl.cat

\begin{abstract}
Resumen
La escritura de Paul Nizan se caracteriza por integrar abundantes imágenes donde el agua ocupa un puesto central. En ocasiones dicho recurso obedece a estrategias de verosimilitud. Sin embargo, abundan los casos donde la presencia acuática constituye un actante más del relato mediante el cual se vehicula el mensaje del mismo: el agua domina entre los elementos paisajísticos a la vez que determina la idiosincrasia de algunos individuos que pueblan el marco geoespacial de las novelas. El presente artículo muestra cómo las imágenes acuáticas, no solo traducen la emoción estética de Paul Nizan, sino que permiten aflorar un imaginario más profundo que responde a una ontología singular del escritor. En particular destaca el uso del agua en sus distintas manifestaciones para aludir a la muerte, tema recurrente en el pensamiento del autor. Se utilizarán como vector de análisis las tesis de Bachelard y de Durand esencialmente para corroborar que las alusiones nizanianas a la metáfora acuática sobrepasan el ámbito de la subjetividad individual.
\end{abstract}

Palabras clave: Paul Nizan; agua; imaginario; ontología; muerte.

\section{Résumé}

En parcourant les romans de Nizan le lecteur retrouve souvent des images qui font appel à la métaphore aquatique. Dans certains cas ce recours se doit à des stratégies de vraisemblance. Maints passages toutefois accordent à la présence aquatique le rôle d'un actant du récit par lequel est transmis le message du texte: l'eau abonde parmi les ornements du paysage alors que souvent cet élément détermine certaines tendances des individus qui peuplent le cadre géospatial des romans. Nos réflexions tenteront de prouver que dans le recours aux images superficielles de l'eau, l'émotion esthétique de Paul Nizan rejoint une pensée plus profonde contribuant à étoffer le canevas du récit ainsi qu'à fonder une ontologie singulière de l'écrivain. Le recours à l'eau dans ses diverses manifestations est à remarquer tout particulièrement, afin de se reporter à la mort, un sujet récurrent de la pensée de l'auteur. Seront évoquées les thèses de Bachelard et de Durand afin de prouver que les arguments nizaniens sur la métaphore aquatique dépassent le volet de la subjectivité individuelle.

Mots-clés: Paul Nizan; eau; imaginaire; ontologie; mort.

\begin{abstract}
Often in Nizan's novels, many images appear that evoke the aquatic metaphor. In occasions the mentioned resource complies with strategies of credibility. Nevertheless, in many cases the aquatic presence constitutes one more actant of the narrative by means of which the author shows his message: this happens for the description of landscape elements or even in the paragraphs which illustrate the idiosyncrasy of some individuals who live in this frame. The present article showcases how the aquatic images translate Paul Nizan's aesthetic emotion, at the same time that it shows the deeper imaginary which translates the singular writer's ontology. Specially the use of the water stands out in its different manifestations to evoke the death, a crucial topic in the author's thought. Bachelard and Durand's theses will be in use as a main vector of analysis to prove that Nizan's allusions to the aquatic metaphor exceed the individual subjectivity.
\end{abstract}

Keywords: Paul Nizan; water; imaginary; ontology; death. 
A menudo el análisis de la obra de Paul Nizan ha privilegiado la orientación ideológica en detrimento de su calidad literaria. Sin embargo, el hecho de que este autor pueda seguir interesando a los lectores del siglo XXI parece avalar que el estilo de su escritura contiene algo de universal que trasciende las preocupaciones de su época. En ese sentido cabe destacar las tesis de Pascal Ory cuando en su prólogo a Le cheval de Troie observa los componentes de la trama y destaca la naturaleza como un actante más allá del simple decorado. Tal hipótesis le permite calificar el texto de «roman matérialiste» (Nizan, 2005:13). Dicho calificativo podría aplicarse a otras dos novelas de Nizan en lo que se refiere al elemento acuático. El presente análisis tiene como objeto probar en qué medida el novelista recurre al agua más allá de un complemento descriptivo, a modo de recurso clave para transmitir el mensaje de cada relato.

Los escenarios acuáticos bretones de Antoine Bloyé, Bourg-en-Bresse en Le cheval de Troie o los barrios de París, las islas griegas o la Normandía de La Conspiration obedecen a un esfuerzo por alcanzar la verosimilitud de las narraciones, aspecto que hay ha sido abordado por Amel Fakhfakh (1996). No obstante, para nuestro estudio nos parece más adecuado recurrir a la argumentación fundada por Gaston Bachelard (1987). Con él compartimos el presupuesto de que la asociación de imágenes poéticas en la escritura de un autor sobrepasa su propia subjetividad y se ancla en su relación con las sustancias de la física cualitativa. Asimismo nos referiremos a las tesis de Gilbert Durand (1990) o de Chevalier et Gheerbrant (1982), cuyos argumentos aportan una óptica complementaria.

La personalidad del sujeto proclive a la metáfora acuática se caracterizaría por su proximidad con la muerte: «L’être voué à l'eau est un être en vertige. Il meurt à chaque minute, sans cesse quelque chose de sa substance s'écroule. La mort quotidienne n'est pas la mort exubérante du feu qui perce le ciel de ses flèches; la mort quotidienne est la mort de l'eau» (Bachelard, 1987: 9). Dicha descripción coincide con la mentalidad de Paul Nizan, cuyas reflexiones acerca de la muerte rozan lo obsesivo. El propio escritor parece hacerse eco de las tesis del crítico a juzgar por los términos que presta al narrador de Le Cheval de Troie. Al referirse a Lange cuando éste participa en la manifestación, afirma: «Il y a des lieux accordés à chaque homme: certains aiment les rivières, ou la mer, ou la neige; d'autres les grandes rues où ils peuvent coudoyer beaucoup d’êtres, se mêler aux groupes qui se font...» (Nizan, 2005: 122)

Desde esa óptica las funciones del elemento acuático en la escritura nizaniana son numerosas y significativas. Como coadyuvante descriptivo, en virtud de las características del agua se establecen metáforas y comparaciones que perfilan el carácter de los personajes: los estudiantes de La Conspiration, empeñados en conseguir la revolución, interpretan la lluvia como una muestra de la banalidad cotidiana contra la que se rebelan (Nizan, 2003: 219,242). En Le Cheval de Troie les «bulles échappées aux vases d'un étang» corren paralelas a las miserias de la vida obrera, privada de lo fundamental como puede ser el descanso nocturno. La alusión traduce además otros matices negativos propios de las aguas estancadas, inmóviles (Bachelard, 1987: 96). Muchos otros ejemplos contribuirían a ilustrar ese procedimiento metonímico en el que no nos detendremos pero que confirma ya la inclinación de Nizan hacia el elemento líquido.

El autor emplea el agua como vector referencial para caracterizar el tiempo o el espacio: domina en el jardín de los Rosenthal, se halla presente también en la descripción de l’École Normale donde el estanque de peces alude ya a un cierto inmovilismo; las fuentes naturales acompañan a los chiquillos durante la infancia de Antoine Bloyé y el canal o el río presiden los momentos de diversión del personaje epónimo tras el estallido de la guerra. Asimismo, en Nantes el carácter acuático, además de responder a una realidad geográfica, cobra un papel simbólico: «Nantes est une ville où le commerce de mer, les banques, les usines, les faces blanches des femmes dévotes, la mort et l'inquiétude sont les éléments mystérieux d'une vie que nulle autre ville française n’impose à ses habitants.» (Nizan, 2005b: 299). Aunque se mencionen los efectos económicos de esa condición, el narrador subraya sobre todo las consecuencias morales. Por ello la ciudad se convierte en espacio de muerte y es allí donde al final de su vida Bloyé sufre la mayor decadencia.

Por su parte los protagonistas de Le Cheval de Troie parecen determinados por la presencia del río que en diversos pasajes se convierte en su punto de referencia. El íncipit se abre in medias res presentando a las parejas de jóvenes en su descanso rutinario. Al amparo de una naturaleza que, con todo, les importuna de manera recurrente, el río limita la tregua de los protagonistas frente al mundo del trabajo. En él el autor condensa las alusiones a la vida ordinaria de los obreros, a sus miserias urbanas. Durante la siesta, mientras los demás duermen, Bloyé vaga por la ribera: sustentándose entre la arboleda, como si no fuese amo de su cuerpo, intenta percibir el soplo de la vida en los peces. Con la ausencia de éstos, en lugar de una contemplación narcisista, busca rememorar el rostro de sus amigos: sus caras se desvanecen a la vez que ellos se dispersan negándole el reflejo en el agua. El fragmento incide en cómo las penalidades de la condición obrera provocan 
en dichos individuos una disolución de sus rasgos propios en beneficio de una emergente masa indiferenciada, fenómeno presente también en otros textos, según ha comentado André Not (2003: 122).

Los datos climatológicos relativos al medio acuático aparecen consignados a menudo para proporcionar al lector una explicación sobre la conducta de los personajes (Nizan, 2003: 24). El agua puede resumir la esencia de ciertos periodos históricos (Nizan, 2003: 66), aunque el narrador suele primar su vertiente heracliteana: el agua fluye sin cesar y nunca uno se baña dos veces en la misma. «L’eau qui coule est la figure de l'irrévocable» (Durand, 1990: 104) señala G. Durand desde una óptica que sintetiza perfectamente la sensación del tiempo tal como lo experimenta Antoine y que reza así: «Les années passaient, comme des bateaux sans amarres qu’enlève le courant d’un fleuve» (Nizan, 2005b:127).

Una tercera función de mayor trascendencia convierte el agua en constituyente esencial de ciertos protagonistas. Tomemos a Antoine Bloyé como ejemplo. El agua determina su ciclo vital. Durante su infancia las circunstancias geográficas de Dirinon lo sitúan en una zona dominada por la presencia acuática. La descripción genérica del territorio evoca la rada de Brest, la Bretaña. De ella destaca la abundancia de fuentes milagrosas que dieron lugar en su época a la construcción de santuarios. No se trata de un escenario habitual puesto que se acompaña de matices sobrenaturales aportados por la madre de Antoine, nieta de un hechicero. A ella le corresponde transmitirle el misterio de su linaje a través del agua, misión que cumple -según subraya el relato- al darle a beber aguas gélidas e inculcarle sus creencias sentándolo en las rocas marinas viajeras para evitarle el mal de Divy. Sin embargo, el narrador no escapa al hecho de que, en términos de Bachelard, «L'eau n'est plus une substance qu'on boit; c'est une substance qui boit; elle avale l'ombre comme un noir sirop» (Bachelard, 1987: 77). Pese a dicha supuesta comunión con la naturaleza, la iniciación a la vida rural fracasará y se convertirá en una de las sucesivas traiciones de Antoine (Ory, 1980: 147). A esa omnipresencia se añade una nueva connotación negativa del elemento acuático cuando el relato evoca el estanque de Rouazlé, espacio de juego del futuro anti-héroe. Según la poética bachelardiana, este agua quedaría clasificada bajo el epígrafe de «aguas durmientes, profundas, próximas a la muerte» (Bachelard, 1987: 90). El procedimiento creativo de Nizan inscribe pues, al personaje de Antoine en un movimiento circular donde los extremos se unen: condicionado desde que viera la luz por una «liquidez» engañosa, ésta acaba por convertirse en causa mortal. Lejos de aparecer como dos momentos aislados, el texto hace hincapié en lo reiterativo y problemático de dicha constitución: a sus treinta y cinco años su físico confirma su calidad acuosa puesto que se le dota de una «peau sanguine». A lo anterior se añade su temperamento de «nerveux sanguin», diagnóstico formulado por la autoridad médica del doctor para referirse a su malestar físico. Argumento retomado por la esposa de Antoine para justificar sus fracasos morales al enfrentarse a las oportunidades laborales abortadas en Inglaterra o China. Por consiguiente, no es de extrañar que sus dolencias físicas de la madurez obedezcan a dicha constitución: la arterioesclerosis o la aortitis lo convierten en un esclavo de su complexión líquida. De hecho, Antoine sucumbirá víctima de su propia condición líquida. La ironía del escritor se palpa en el sobrenombre que los obreros han asignado a su jefe, «le Pur-Sang». Bachelard constata hasta qué punto las imágenes asociadas a la sangre nueva manifestación del agua profunda- suelen presentar connotaciones negativas (Bachelard, 1987: 84). G. Durand retoma dicho argumento al asegurar: «Cette eau noire n'est finalement que le sang, que le mystère du sang qui fuit dans les veines ou s’échappe avec la vie par la blessure [...] Le sang est redoutable à la fois parce qu’il est maître de la vie et de la mort, mais aussi parce qu'en sa féminité il est la première horloge humaine, le premier signe humain corrélatif du drame lunaire» (Durand, 1990: 122).

La tragedia individual de Bloyé aumenta su magnitud al afectar a la familia al completo puesto que Marie acusa también una debilidad física atribuida a su condición líquida: «Elle avait toutes les grâces fragiles des petites filles qui sont condamnées à mort; sous sa peau on voyait courir des réseaux de veines: 'Maman, regarde les rivières', disait-elle...» (Nizan, 2005b: 159). Esa irrigación aparece como causa de la congestión cerebral que la conducirá a una muerte súbita, otro eslabón en el drama del protagonista.

El predominio del agua en la constitución de Antoine, su afinidad con esta materia conducen al narrador a tomarla como referencia para ilustrar los sentimientos del personaje. El mar subraya la calma feliz en la que se instala durante el periodo de su compromiso (Nizan, 2005b: 118). La tormenta preside, en cambio, los instantes difíciles que preceden el estallido de la guerra a la vez que anuncian el progresivo aumento del malestar obrero (Nizan, 2005: 146). Desde esa óptica, también el lado más heroico de Antoine se desarrolla en un medio acuático. El fragmento en el que el protagonista remonta la locomotora caída en el río Creuse confirma el estrecho vínculo entre ambos: reencarnación de Jean Valjean, la experiencia vivida constituye un momento único de su comunión con los hombres. Únicamente el trabajo, según subraya el texto, le permite amalgamarse con los equipos de salvamiento. El individuo se muestra en sintonía con la colectividad. 
Ese objetivo noble le impulsa a enfrentarse a las adversidades naturales que el río supone, ya se trate de las víboras escondidas o de sus frías aguas. Evocar dicho éxito ante su hijo, además de destacar su lazo con el elemento acuático, subraya la multiplicidad de circunstancias que debe superar (Nizan, 2005b: 218). Sin embargo, lejos de consagrarlo al estilo de un superhombre romántico, Nizan presenta a un individuo desestabilizado por la sociedad contemporánea, a un ser sometido a un ineluctable y por ende, dramático proceso de desintegración. Fundirse con el mundo natural no basta para liberar a este ser, víctima de su propia ira pese a sus intentos por contrarrestarla. Del mismo modo, la tregua veraniega anual que suele pasar en el Morbihan, donde el escenario abunda en metáforas acuáticas, lo convierte en un marinero por definición. Capaz de surcar mares imaginarios como los de Beauce o el trayecto entre Angers y Nantes, Bloyé trata de compensar su rutinaria vida en el Midi mediante la contemplación de los barcos amarrados en el puerto o a través de actividades como la pesca. El imaginario acuático da cuenta de su afecto por ese lugar. Sin embargo, no se trata más que de un falso oasis puesto que al cabo de cuatro semanas ha perdido su encanto y lo sume en una inquietud similar a la de su existencia ordinaria.

Por añadidura otros personajes aparecen determinados por el agua. A nuestro juicio, M. Guyader reproduce un esquema que, por el paralelismo entre él y su yerno, insiste en el sentimiento de fracaso que predomina en el conjunto de la narración. El mar ha proporcionado a M. Guyader reiteradas experiencias de felicidad en lo relativo a su trayectoria profesional. Miembro de la marina imperial, sus misiones por mares y océanos le brindaron una cierta posición social y un reconocimiento que sólo el cambio a un régimen republicano enturbia. La insistencia con la que el narrador incide en las proezas de ese mecánico, el ensueño marítimo al cual se abandonaba durante su jornada en la oficina indica su predilección por ese modo de vida. Pero además de los acontecimientos políticos y por tanto, externos, ha forjado su destino la influencia privada, encarnada en su esposa cuyas exigencias le imponen una dura elección entre ella y sus hazañas como hombre de mar. El desgraciado balance de esa «longue et dure traversée» entabla una clara similitud con la trayectoria de Antoine ${ }^{1}$, lo cual permite interpretar a este personaje a modo de un resorte dramático que incide en la condición antiheroica del protagonista.

Más allá de esas constataciones externas, el agua materializa la presencia tangible de la muerte. A modo de ejemplo nos referiremos al capítulo XX de Antoine Bloyé: en el campo semántico utilizado abundan los términos relativos al medio acuático $^{2}$. Con ellos se describe la toma de consciencia del protagonista sobre su propio fin:

Moi, je dois mourir; ce n’était plus comme le récit d’un crime, d’un malheur [...] c’était un avertissement lancé des profondeurs remuantes et humides du corps. [...] Antoine était un homme corporel, il n'avait pas une conscience assez pure pour qu'elle se désintéressât du corps qui la nourrissait et lui fournissait depuis tant d'années, à chaque seconde, la preuve admirable de l'existence. La mort est le cataclysme du corps. (Nizan, 2005b: 272-273)

La muerte emerge del interior para ir minando el cuerpo que hasta entonces la ha albergado. Ese efecto se revela mucho más trágico en la mente de un escritor cuyos principios sostienen que «il n’y a pas d'autre vérité qu’un corps» (Nizan, 2005: 230) ${ }^{3}$. Ya hemos mencionado la importancia de la sangre en la constitución del personaje epónimo. Dicha característica cobra mayor relevancia al prefigurar el mensaje que va a exponer en su posterior novela. En Le Cheval de Troie el fallecimiento de Catherine viene provocado por su embarazo, por el ser que lleva en sus entrañas. Lo que late en su carne se convierte para ella en su propio caballo de Troya al igual que los obreros suponen una erosión constante de las convenciones burguesas. Se instaura así un paralelismo entre el colectivo de trabajadores y el femenino que sugiere la modernidad de Paul Nizan en su óptica sobre la mujer. La condición líquida aparece pues, como un factor peligroso contra el que los individuos se rebelan aun sin posibilidades de victoria: Berthe secunda el complot de los hombres y el día de la manifestación se esfuerza por darles alimento como si pudiera contrarrestar el peligro de que cedan a una eventual disolución ${ }^{4}$. No nos detendremos en el pasaje que describe la muerte de Catherine, puesto que ya ha sido comentado por

\footnotetext{
${ }^{1}$ «Mais cet homme qui avait laissé échapper comme bien d'autres le seul avenir qui l'eût peut-être comblé, n’était pas un homme heureux» (Nizan, 2005b: 114).

2 «canaux de l'angoisse et du souvenir», «affluents», «source nouvelle», «inonde» (Nizan, 2005b:272).

${ }^{3}$ También en Le Cheval de Troie el narrador insiste en el mismo aspecto: « Nous ne possédons que nos corps» (Nizan, 2005: 228).

${ }^{4}$ «il faut manger -les somme-t-elle- à présent: vous devez vous sentir vous en aller» (Nizan, 2003: 204).
} 
André Not. Tan solo evocaremos, citamos al mismo Not, la «porosité de l'être-Catherine» (Not, 2003: 146-149) que traduce perfectamente esa incapacidad de retener los líquidos que encarnan su propio yo. Los términos que resumen su hemorragia la presentan como una víctima de su fluidez incontenida ya que su sangre sobrepasa el cuerpo, la cama, alcanzando sin remedio el suelo. No le extrañará al lector la alusión a las medusas en referencia a la pérdida de percepción de la realidad circundante, imagen muy significativa tanto desde una óptica realista como simbólica: ese animal depredador capaz de aniquilar la vida del hombre añade a su perversidad las connotaciones mitológicas, según las cuales la criatura así nombrada simbolizaba la imagen deformada de sí misma (Gheerbrant, 1990: 482). La elección del novelista es comprensible porque debe mostrar hasta qué punto durante su traspaso Catherine percibe su entorno deforme. Además, el caso de la protagonista se encuentra íntimamente unido al de Paul por su mensaje ideológico y también por la forma: como ella, el manifestante debe enfrentarse a los límites de sus líquidos. Su fin arranca con esa uña herida que sangra y termina por una bala que le provoca una perforación intestinal a la vez que le atraviesa la vejiga. Por citar los mismos términos de Berthe, il «s'en est allé» (Nizan, 2005: 204). Aunque el traspaso de Catherine se sitúa en una perspectiva opuesta a la de Antoine Bloyé pues, en este último caso, el fatal desenlace se debe a que «aucun sang ne coula» (Nizan, 2005b: 310), se adivina un principio común, una convergencia en el mensaje del autor. Propone así hasta qué punto el individuo es deudor de su propia constitución, en la que un desequilibrio de sus líquidos desencadena consecuencias funestas.

En ese mismo sentido el suicidio de Bernard en La Conspiration enlaza con la presencia acuática: sus últimos instantes se describen como una tempestad, antes de que el sedante lo conduzca a «les vases gluantes du sommeil». Nizan retoma así la figura del ahogado, que ya aparecía en esta misma novela entre los elementos que centraban la conversación de Philippe con Pauline (Nizan, 2003: 37). Sin embargo, es en Antoine Bloyé donde el autor recorre a ella de forma obsesiva. Dos pasajes, a nuestro juicio, merecen nuestra atención: el desenlace alude al tema de forma manifiesta mediante la expresión «autour de lui la vie était soudain étalée comme la mer». Antoine es engullido por esa agua/vida que no puede dominar, que jamás ha conseguido controlar puesto que en ningún caso la vida le ha permitido expandir sus gustos más allá del escenario burgués. Su última imagen recuerda la del íncipit que, a los ojos de su hijo Pierre, se define en los siguientes términos: «Cette ombre livide dans l’ombre montait comme la figure d'un noyé qui revient de ses explorations profondes et Pierre écartait ses regards de l'eau immobile derrière laquelle commençait le pays des morts» (Nizan, 2005b: 310). La coincidencia entre ambos fragmentos es palmaria y cobra mayor importancia por su disposición estructural. El desenlace cierra el círculo fatal al regresar a su inicio: la trayectoria del personaje principal se convierte en punto de partida, de modo que la vida no puede escapar a la muerte bajo ningún concepto. El narrador había profetizado dicho mensaje en el capítulo XIII cuando asimilaba la vida humana al curso de un río que iba a parar a la mar. Un mar que engullía sin tregua, de manera que la definición del curso de la existencia se asocia por naturaleza a la muerte (Nizan, 2005b: 179). La relación intrínseca entre ambos actos fundacionales del individuo recaba en la metáfora acuática puesto que se refiere al nacer como un desprendimiento del ser humano de los líquidos que le envuelven. Así se describe el parto de Anne Guyader. Por ese motivo se identifica a la madre con una nadadora pues, seguimos las tesis de Bachelard, la natación conlleva una experiencia enérgica en la que el cuerpo mide sus propias fuerzas con las del agua (Bachelard, 1987: 225). Dar a luz a ese fruto de sus entrañas a través del relato de una muerte evoca su particular combate: una lucha contra las secuelas provocadas por el fallecimiento de su primera hija, a la que se añade la profunda tendencia de su marido a la nada. Al igual que para los protagonistas de Le Cheval de Troie, Nizan opta por una postura filosófica capaz de dar sentido a la muerte individual, sin una necesaria justificación de la vida tal como se produce en las esferas religiosas de su entorno.

Ahondando en las tesis de Bachelard, la preocupación nizaniana por la muerte permitiría advertir en su obra el complejo de Caronte: la muerte, lejos de ser el último viaje, constituiría el primero de ellos. El féretro no es otra cosa que su barca (Bachelard, 1987: 100). Desde un punto de vista global Antoine Bloyé ilustra esa tesis ya que el traspaso del protagonista abre paso a la contemplación del desarrollo de su propia trayectoria, de su existencia. La asociación con el barquero mítico se acentúa mediante anécdotas precisas: cuando el ataúd desciende a la bodega y sus acompañantes dan el pésame a la viuda, esta última evoca una práctica de antaño sobre la conservación de los cuerpos. La respuesta del vigilante al respecto es elocuente: «Il y a une nappe d'eau souterraine... Les bières sont dans l'eau... ça conserve les gens tout à fait [...]» (Nizan, 2005b: 43). La idea traslada a Anne Guyader a esa otra existencia post mortem, en la que ella confía y que concibe a modo de «navigation immobile et glacée» (Nizan, 2005b: 43). 
El agua que Nizan asocia a la muerte no se trata de un líquido cualquiera, sino un líquido pesado, profundo cuyos efectos impiden la renovación y por consiguiente, la vida. Dicha concepción explica que en Le Cheval de Troie pueda advertirse la presencia de otros complejos -por seguir con la terminología bachelardiana- afines a la muerte. En concreto el complejo de Ofelia, que proporciona un rostro femenino al traspaso. En virtud de esa característica cuando Lange se halla atrapado entre los manifestantes y los oradores, experimenta una ensoñación liberadora que fabula su propio deceso bajo la protección de una figura femenina sobrevolando el océano. Pese a que no insistiremos en las connotaciones políticas de dicho enfrentamiento (Lecarme, 2002: 89-103), debe considerarse que se trata de la única ocasión en la que este individuo ajeno a cualquier actitud de conjunto logra asimilarse a una acción común. Por ello el episodio se inicia con un descenso a los infiernos tras el cual Paul será capaz de superar sus traumas sexuales y de contemplar sin angustia su propio tránsito.

El valor que concede el novelista a la materia líquida justifica también la frecuente comparación con los seres propios de este ecosistema. Las metáforas alusivas al universo piscícola tienen como objetivo acentuar la omnipresencia de la muerte. En Antoine Bloyé la grúa que recupera los cuerpos maltrechos debido al accidente se convierte en un «grand poisson des abîmes» (Nizan, 2005b: 139); a los ojos de su mujer, Antoine se asemeja a un arenque cuya actitud impide el posible ascenso burgués del matrimonio truncando así, las esperanzas de la esposa. Con dicha personalidad Bloyé solo puede ser tratado por un neurólogo cuyo consultorio se parece a un acuario (Nizan, 2005b: 285), sin olvidar -por fin- que uno de los objetos más entrañables de los Bloyé es la bola de cristal donde el paisaje «se retournait comme un poisson» (Nizan, 2005b: 256). Más allá de la primera novela de Nizan, la asimilación piscícola cobra una importancia singular en Le cheval de Troie. Si en una postura muy progresista el escritor interpreta la sexualidad de los obreros, sobre todo de sus mujeres, como factor de sujeción del individuo, el lector percibe la amargura de pasajes como el siguiente: «Dans un train, un jour, un homme qui avait dit être docteur racontait avoir vu à l'hôpital une femme qui avait un poisson dans le ventre, une carpe, disait-il; le chirurgien, en sentant cette présence insolite et froide sous sa main, avait poussé un cri». (Nizan, 2005: 98) Son numerosas las religiones antiguas en las que el pez simboliza la fecundidad (Cazenave, 2004: 543). El novelista recupera esa atribución para denunciar precisamente los efectos adversos que conlleva para los más desheredados: el paralelismo entre la historia colectiva y la de Catherine resulta manifiesto. En ambos casos los protagonistas llevan la extinción en sus entrañas: también Lange se convierte en pez cuando pierde su sombrero durante el combate...

El resto de la fauna marina contribuye a perfilar esa impresión de deglución: mencionábamos antes a Catherine descrita a imagen de una medusa. Dicha especie biológica regresa para colonizar los cielos parisinos el día en que Rosenthal conduce a sus amigos a casa de Régnier; en Le Cheval Bloyé recurre a la analogía entre los habitantes parisinos y las lombrices marinas para denunciar la actitud de los comerciantes símbolo de lo burgués y contra lo que el antihéroe expresa su indignación; en la Conspiration se adivina un sentido afín en la anémona de mar que Bernard utiliza para aludir a la naturaleza de su familia. Ese pólipo cuyos tentáculos sirven para apresar víctimas, atestigua el ahogamiento del círculo familiar sobre el hijo.

En general el agua aparece como una clave de lectura del aprisionamiento en que viven sumidas las criaturas nizanianas. Un claro ejemplo se percibe en Le cheval de Troie cuando escenifica las reuniones previas a la manifestación. Estas se enmarcan en espacios presididos por cuadros cuyo motivo central se basa en el agua: en el Café Coopératif se representa a una mujer de melena rubia, apoyada en una palmera y en actitud contemplativa frente al paisaje de un volcán humeante con el mar de fondo (Nizan, 2005: 101); en la Sala que reúne a los partidarios de la derecha los azulejos reproducen la galera de un faraón que desciende el Nilo, acompañado de flores de loto y de mujeres prácticamente desnudas (Nizan, 2005: 148). El parentesco entre ambas representaciones evoca la tragedia personal que, más allá de las convicciones políticas, concierne al individuo en cualquiera de sus posiciones y que culmina con el enfrentamiento posterior en plena calle: en ambos casos al individuo, hostigado por la muerte, le resulta imposible escapar a su drama.

Si existe un personaje femenino en La Conspiration que encarne la materia acuática, ése es Marie-Anne. Durante la visita de Bernard a su hermana predominan las referencias al mar. Sin duda la influencia geográfica justifica esas alusiones en pro de la verosimilitud. Sin embargo, la virtud marina de fomentar la ensoñación (Bachelard, 1987: 190) permite asimilar ese momento en la trayectoria del protagonista a su paraíso perdido. La felicidad del joven durante su periplo a las Cícladas añade además las connotaciones míticas atribuidas al mundo oriental. A lo anterior se le suma el hecho de que Bernard busque en ese desplazamiento la ocasión de reconciliarse con sus amigos y con su familia. El viaje adquiere un matiz iniciático en el sentido de que el protagonista se beneficia de una tregua para encauzar su futuro. Las islas parecen un medio apropiado puesto que, según Bachelard, el agua alberga la posibilidad de revelar al hombre su destino (Bachelard, 1987: 190). Por consiguiente, en compañía de Marie-Anne, Bernard «découvrait enfin qu’il était capable de se détendre: 
on ne l'avait jamais tant aimé» (Nizan, 2005: 149). Elemento primordial de ese edén, el agua propicia la revelación del amor. Así se explica su presencia en pasajes posteriores donde el antihéroe prosigue su búsqueda metafísica en compañía de Catherine. Enmarcada por los acantilados que dominan la región de Brey, la residencia normanda de los Rosenthal se transfigura y adquiere la forma de un navío (Nizan, 2005: 154) susceptible de albergar a los amantes. No es la primera vez que Nizan remite al medio acuático como escenario para permitir al individuo concentrarse en su intimidad: también Paul, en Le Cheval de Troie, se había dirigido a la orilla del río para hallar el refugio apropiado y poder concentrarse en el recuerdo de la compañera a quien había tenido que abandonar...

En definitiva, la presencia de la materia acuática en la obra novelesca de Paul Nizan dista de ser un hecho fortuito. Cual eco de la imaginación del autor, ese Prometeo-Encadenado - expresión que tomamos de Pascal Ory (Ory, 1980: 260) el agua representa un pilar fundamental de la arquitectura narrativa. Dicha cualidad ofrece a las imágenes del universo líquido un alcance ontológico y contribuye a precisar la cadencia de la meditación filosófica llevada a cabo por el escritor.

\section{Referencias bibliográficas}

BACHELARD, Gaston (1987). L'eau et les rêves. Paris: Corti.

CAZENAVE, Michel (2004). Encyclopédie des symboles. Paris: Librairie Générale Française.

Chevalier, Jean et GheERBrant, Alain (1982). Dictionnaire des symboles. Paris: Robert Laffont/Jupiter.

Cohen-Solal, Annie (1980). Paul Nizan communiste impossible. Paris: Bernard Grasset.

DuRAND, Gilbert (1990). Les structures anthropologiques de l’imaginaire. Paris: Dunod.

FaKнғакH, Amel (1996). La lecture du réel dans l’œuvre de Paul Nizan. Tunis: Alif, les Éditions de la Méditerranée et Faculté des sciences humaines et sociales de Tunis.

LeCARme, Jacques (2002). «Le crime de M. Lange. Sartre dans le texte de Nizan» en Aden. Paul Nizan et les années trente, $\mathrm{n}^{\circ}$ 1, pp. 89-103.

NizAn, Paul (2003). La Conspiration. Paris: Gallimard, «Folio». [1938].

NizAN, Paul (2005). Le Cheval de Troie. Paris: Gallimard. [1935].

NizAn, Paul (2005b). Antoine Bloyé. Paris: Grasset. [1933].

Not, André (2003). «L’écriture du corps dans Le Cheval de Troie» en Aden. Paul Nizan et les années trente, $\mathrm{n}^{\circ}$ 2, pp. $146-149$.

ORY, Pascal (1980). Nizan. Destin d'un révolté. Paris: Ramsay.

Ory, Pascal (2005). «Préface» en Nizan, P. Le cheval de Troie. Paris: Gallimard. 